\title{
O Professor Florestan Fernandes e nós
}

\author{
JOSÉ DE SOUZA MARTINS
}

\begin{abstract}
“...alcancei a estatura de um artesão que
domina e ama o seu mister, porque sabe como deve praticá-lo e para o que ele serve"
\end{abstract}

(Fernandes, 1977, p. 175)

RESUMO: O artigo trata da importância do legado intelectual e político do Professor Florestan Fernandes, presente em seus sucessores no Departamento de Sociologia da Universidade de São Paulo.

Florestan Fernandes, sociologia brasileira, sociologia de São Paulo.

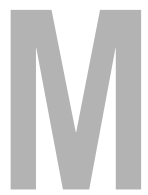
ais do que um débito de formação de quadros em relação ao Professor Florestan Fernandes, o Departamento de Sociologia da Faculdade de Filosofia da Universidade de São Paulo tem ainda um nome respeitado que devemos a ele e ao grupo de docentes de que passou a fazer parte, em 1945. E que devemos também ao sólido grupo de cientistas sociais que foram seus alunos, que ele recrutou para o magistério na Universidade e que constituiu a segunda geração de sociólogos brasileiros de nossa escola.

Talvez fique difícil entender o que isso significa nestes dias de prestígios fáceis, pessoais e intransferíveis, em que um departamento acadêmico não é mais do que um aglomerado de pesquisadores, cada qual navegando em suas próprias águas. Os tempos são outros, mas não melhores.

O Professor Florestan empenhou-se, juntamente com vários de seus contemporâneos, em fazer com que a preciosa dádiva da missão universitária francesa, que fundara a Universidade de São Paulo, se tornasse um bem co- 
mum. Ele disse, mais de uma vez e com razão, que a criação da nossa Universidade constituiu um acontecimento de conseqüências culturais e sociais muito mais radicais do que a Semana de Arte Moderna. Lévi-Strauss, nosso primeiro professor de Sociologia, expôs com a clareza de testemunha lúcida em que contradições se apoiava a criação da Universidade e quais foram seus resultados sociais inesperados. Tomo a liberdade de transcrever um parágrafo dessa espécie de livro de tombo da criação da Universidade de São Paulo, que é o seu Tristes trópicos:

"Coisa curiosa: a fundação da Universidade de São Paulo, grande obra da vida de Georges Dumas (articulador da missão universitária francesa enviada ao Brasil, JSM), devia permitir a essas classes modestas começar a sua ascensão, obtendo diplomas que lhes abriam acesso às posições administrativas, de tal forma que a nossa missão universitária contribuiu para formar uma nova 'elite', que se ia afastar de nós na medida em que Dumas, e o Quai d'Orsay atrás dele, se recusavam a compreender que era ela a nossa criação mais preciosa, embora se entregasse à tarefa de solapar uma classe feudal que nos havia, é verdade, introduzido no Brasil, mas para servir-lhe em parte de caução e em parte de passatempo" (Lévi-Strauss, 1957, p. 13).

Quando se fala em sociologia crítica na USP, deve ter-se em conta essas contradições de origem, que na benéfica confusão de propósitos de 1934 de fato comprometiam a Universidade com a democratização da cultura. Com a sua Faculdade de Filosofia, Ciências e Letras, criada nesse ano, abria os cursos superiores, indistintamente, aos bem nascidos, diletantes ou não, e aos de origem modesta, tanto os que entreviam na escola um caminho de ascensão social, como os que nela viam uma porta aberta à expressão de vocações até então bloqueadas pelo nosso regime universitário de escolas isoladas, devotadas ao direito, à medicina e à engenharia. As razões desse projeto foram também assinaladas por Lévi-Strauss:

"Nesse Brasil, (...) a cultura permanecera, até uma época recente, uma distração dos ricos. Eé por ter essa oligarquia necessidade duma opinião pública de inspiração civil e laica, para contrabalançar a influência tradicional da Igreja e do exército, bem como do poder pessoal, que criou a Universidade de São Paulo, decidindo abrir a cultura a uma clientela mais larga” (Lévi-Strauss, 1957, p. 103).

Se havia tais intenções na obra dos fundadores da USP, havia também intenções de reformular o sistema educacional e democratizar o ensino, como se vê nos escritos e nas ações de Fernando de Azevedo. 
MARTINS, José de Souza. O professor Florestan Fernandes e nós.Tempo Social; Rev. Sociol. USP, S. Paulo, 7(1-2): 179-186, outubro de 1995.

A fundação da USP criou um meio social propício à pesquisa, ao debate, à indagação sobre a sociedade brasileira e seus dilemas. A educação era desde o início concebida como o instrumento maior de difusão de uma consciência científica da sociedade, um instrumento de mudança social através da ação dos educadores. Havia, portanto, mais do que Lévi-Strauss podia ver e, como ele reconhecera, mais do que as oligarquias paulistas podiam ver.

As duas primeiras gerações de brasileiros formadas pelos europeus assumiram a responsabilidade de levar adiante as promessas contidas no legado da missão universitária francesa e as possibilidades contidas nas contradições representadas pela fundação da USP. Mais: criaram uma cultura acadêmica que sintetizava esse legado e as fecundas inquietações e inspirações dos jovens intelectuais paulistas dessa época. Dificilmente encontraremos nas diferentes biografias das personagens dessa história perfis e mentalidades convergentes. A convergência estava nas enormes possibilidades de interferência numa sociedade marcada por contrastes agudos, como assinalaria em livro posterior Roger Bastide, outro ilustre professor de sociologia de nossa escola. E estava, também, num notável devotamento à idéia da educação como missão principal. O vigor dessa idéia está em obras de Fernando de Azevedo, de Antonio Cândido, de Florestan Fernandes e de pesquisadores e docentes que os sucederam.

O professor Florestan nunca concordou que o notável grupo de sua geração, na Faculdade, em especial o grupo que ele mesmo constituiu e dirigiu, pudesse ser classificado como uma escola sociológica. Ele considerava essa idéia uma falta de imaginação. Recusava o rótulo de "escola" porque a constituição de seu grupo de pesquisadores "não supunha que devêssemos todos pensar da mesma maneira, como uma escola, com certa 'doutrina', (Fernandes, 1977, p. 183). No entanto, é possível que ele não tivesse razão. Certamente, o chamado "grupo de São Paulo" não chegou a constituir uma escola de unanimidade teórica, como a chamada "escola de Chicago" (que ele tinha como referência ${ }^{1}$ ). Isso porque seus vários membros, como facilmente pode ser visto em suas obras, tenderam a desenvolver seus próprios caminhos, até mesmo produzindo contribuições teóricas originais. A própria obra do professor Florestan tem uma dinâmica interna evidente, embora não seja ela marcada por rupturas radicais entre um momento e outro. Mas, se há descontinuidades entre, por exemplo, Mudanças sociais no Brasil e Sociedade de classes e subdesenvolvimento, há nesses mesmos livros, sem dúvida, um claro desenvolvimento de preocupações relativas à desencontrada historicidade da sociedade brasileira, aos seus ritmos desiguais e às contradições que dela decorrem.

No entanto, penso, há sim uma "escola sociológica de São Paulo" no que se refere às indagações mais ou menos comuns que orientaram os trabalhos de seus pesquisadores e orientam ainda as investigações de seus alunos e continuadores. A grande obra dessa escola vai além dos trabalhos notáveis que produziu. Ela está nas questões formuladas, nas perguntas que
1 A possibilidade de converter São Paulo numa espécie de laboratório especializado da investigação sociológica, como ocorrera com Chicago, "atraía o melhor de minha imaginação", disse Florestan Fernandes num texto a u t ob i o g ráf i c o (cf. Fernandes, 1977, p. 170). 
nortearam suas pesquisas e suas interpretações do Brasil. Ela está no modo como a realidade foi problematizada pela interpretação sociológica, está nos temas de investigação que foram por ela definidos. $O$ trabalho científico não expressa sua qualidade apenas pelas respostas que dá, mas sobretudo pelas perguntas que faz, pelos problemas que formula. O grupo de São Paulo dessa época foi responsável pela formulação de indagações científicas essenciais, que são ainda as que orientam a pesquisa sociológica consistente em nosso país. Quem foge delas, na verdade tende a mergulhar num estilo de trabalho próximo do ensaismo pré-sociológico ou no diletantismo interpretativo de quem pretende exibir erudição e familiaridade com os nomes da moda, sobretudo na Europa, no rumo claro de uma recolonização do pensamento social no Brasil. Neste último caso, um retrocesso evidente. A propósito, Lévi-Strauss já havia observado que entre os primeiros alunos da USP:

"Nossos estudantes tudo queriam saber; mas, em qualquer domínio que fosse, somente a teoria mais recente lhes parecia merecer atenção. Embotados por todos os festins intelectuais do passado, que, aliás, só conheciam de oitiva, pois não liam as obras originais, conservavam um entusiasmo sempre disponível para os pratos novos. No seu caso, deveríamos falar mais em moda que em cozinha: idéias e doutrinas não possuíam aos seus olhos um interesse intrínseco, eles as consideravam como instrumentos de prestígio cujas primícias deviam assegurar-se. Partilhar uma teoria conhecida de outrem equivalia a apresentar-se com um vestido já visto; seria desmoralizante" (Lévi-Strauss, 1957, p. 105).

A grande obra dessa escola está, também, no modo como os métodos explicativos foram desenvolvidos e utilizados. Florestan Fernandes fez um trabalho metodológico de primeira linha no seu tratado sobre o método funcionalista de origem durkheimiana. A retomada desse método por Robert K. Merton, em livro de 1949, foi seguida de interpretações críticas em vários países. Na reedição de seu livro, em 1957, Merton arrolou, dentre outros, os autores cujas obras nesse sentido ele conhecia e considerava dignas de relevo e os respectivos anos de edição: Talcott Parsons (1951), Marion Levy Jr. (1953), Florestan Fernandes (1953), Ralph Dahrendorf (1955), Georges Gurvitch (1955), David Lockwood (1956), Bernard Barber (1956). No "Post-scriptum bibliográfico", diz: "Ensaio sobre o método de interpretação funcionalista em Sociologia, por Florestan Fernandes (1953), é uma monografia informativa e sistemática que recompensa uma leitura ainda que apressada e falível como a minha" (cf. Merton, 1964,p. 93). Na verdade, já em 1952, o professor Florestan havia feito um uso denso desse método em A função social da guerra na sociedade Tupinambá.

Seus alunos Fernando Henrique Cardoso, Octavio Ianni, Marialice 
MARTINS, José de Souza. O professor Florestan Fernandes e nós.Tempo Social; Rev. Sociol. USP, S. Paulo, 7(1-2): 179-186, outubro de 1995.

Mencarini Foracchi e Maria Sylvia de Carvalho Franco, juntamente com outros professores da Faculdade, por seu lado, organizaram o seminário sobre o método dialético ${ }^{2}$ que influiu poderosamente em suas pesquisas e interpretações, muito antes do modismo, desastroso aliás, que fez de Althusser, e do althusserianismo, uma referência que dispensava a leitura do próprio Marx. Tive oportunidade de ouvir uma exposição de Fernando Henrique Cardoso no México, em seminário de que participavam alguns dos nomes principais do debate sobre transição para o capitalismo. Nela, Fernando Henrique expôs o teor de seu livro Capitalismo e escravidão no Brasil Meridional, cuja introdução trata de uma original leitura sociológica desse método. Lembro bem que a primeira pergunta lhe foi feita pelo historiador francês Pierre Vilar que, surpreso, queria saber se aquela interpretação havia sido produzida no Brasil e se já estava publicada.

Embora o professor Florestan não visse no seu trabalho, no de seus contemporâneos e discípulos o que pudesse ser definido como escola, empenhou-se em produzir e estimular a produção do que se poderia chamar de uma "interpretação sociológica brasileira". Ele disse expressamente que

"Pretendia, isso sim, implantar e firmar padrões de trabalho que nos permitissem alcançar o nosso modo de pensar sociologicamente e a nossa contribuição à sociologia" 3 .

Essa proposta ganhou corpo e definição no Projeto Economia e sociedade no Brasil: análise sociológica do subdesenvolvimento, publicado em 1962. Nele, há um ponto de inflexão em relação ao que os contemporâneos e os discípulos do professor Florestan haviam feito até então:

“...vínhamos concentrando grande parte dos projetos de investigação da Cadeira de Sociologia I no estudo macro-sociológico das condições históricosociais de desintegração da ordem escravocrata-senhorial e de formação da sociedade de classes no Brasil"(Fernandes, 1963, p. 303).

O professor Florestan entendia que os países subdesenvolvidos precisam ir além da importação de

"certos produtos do conhecimento científico e tecnológico (...) assimilando, defato, os padrões de pensamento associados à ciência e à tecnologia científica; (...) conseguindo condições para colocá-los em prática, de forma efetiva e criadora, nas situações de existência histórico-social em que se encontrem. (...) Ou adquirem a capacidade de produzir conhecimentos cientificos e tecnológicos originais (...) ou se vêem impossibilitados de pôr a ciência e a tecnologia científica a serviço dos projetos nacionais de desenvolvimento econômico, social e cultural."(Fernandes, 1963, p. 301).
2 A orientação desse seminário está exposta no artigo de J. Arthur Giannotti, "Notas para uma análise metodológica de 'O Capital'", (1960, p. 60-72). Esse foi o primeiro seminário, na USP, sobre o método de $O$ Capital. De 1975 a 1987, houve um segundo e mais amplo seminário sobre o tema, organizado por mim, no Departamento de Ciências Sociais, com alunos de pós-graduação e docentes de várias unidades, em que foi feito o estudo da questão do método em boa parte da obra de Marx.

${ }^{3}$ cf. Fernandes, A Sociologia no Brasil (1977, p. 178). "Na medida em que o nosso trabalho cresceu, nós tivemos de enfrentar os dilemas de tentar construir uma teoria sociológica original, adaptada à situação brasileira". Cf.. Fernandes (1978, p. 28). 
MARTINS, José de Souza. O professor Florestan Fernandes e nós.Tempo Social; Rev. Sociol. USP, S. Paulo, 7(1-2): 179-186, outubro de 1995.

O “grupo de São Paulo" estava propondo uma sociologia que lidasse com as conseqüências do salto histórico que poderia levar à superação das barreiras que mantinham o país em estado de estagnação econômica, de atraso cultural e de dependência política. Quatro projetos se articulavam nesse projeto maior, dando conta de três âmbitos em que havia pontos de estrangulamento a serem objeto da análise sociológica: o empresariado industrial, o Estado e os trabalhadores. Basicamente, o que se desejava conhecer eram os contrastes entre o atrasado e o moderno, e o máximo de modernização que diferentes comunidades e setores haviam logrado. Nesse grande esquema, que na verdade continha um projeto nacional de desenvolvimento e modernização econômica, social e política, a sociologia comparecia não só como instrumento de diagnóstico. Ela comparecia, também, como instrumento de consciência, o que era próprio e característico das preocupações de Florestan Fernandes e do próprio projeto de criação da Faculdade de Filosofia:

“...nos 'países subdesenvolvidos' ainda prevalece a fórmula segundo a qual 'só vê algo sociologicamente, quem quer algo socialmente'. A situação coletiva de existência entrelaça o 'querer comum'e a 'análise sociológica', convertida em instrumento de autoconsciência da realidade" (Fernandes, 1963, p. 309).

Nesse documento, tanto se fala em ressocialização do empresário, cuja conduta econômica ainda está desviada da racionalidade esperada em conseqüência da herança senhorial, nuns casos, e noutros das formas predatórias da acumulação; como se fala, também, em revolução da mentalidade dos trabalhadores, ainda presos a uma cultura do trabalho em que sua atividade carrega as marcas de degradação impróprias da sociedade moderna. Como também se fala na superação dos entraves que a dominação patrimonial representa para a modernização do Estado. A investigação sociológica identificaria e apontaria os entraves ao desbloqueio das vias do desenvolvimento e ao mesmo tempo a sociologia indicaria as formas de intervenção nos problemas causados pela aceleração do desenvolvimento. Tratava-se de submeter os problemas a controle social,

"para reduzir os seus efeitos nocivos sobre a indus-

${ }^{4}$ cf. Fernandes (1963, p. 327). As concepções relativas à intervenção racional na realidade foram expostas em cursos que Florestan Fernandes deu na Faculdade de Filosofia da USP, de 1956 a 1959. cf. Fernandes, Ensaios de Sociologia geral e aplicada (1960, p. 93 e ss.).

trialização, o crescimento econômico em geral e a expansão da ordem social democrática"4.

Esse projeto parece ter pouco a ver com esta frase final do último artigo escrito pelo professor Florestan, publicado no dia seguinte ao de sua morte:

"O subdesenvolvimento, em suma, tem alimentado o desenvolvimento. Esse paradoxo sódesaparecerá quando os de baixo lutarem organizadamente contra a espoliação, exigindo transformações profundas na política econômica, nas funções do Estado e na estrutura da 
sociedade de classes" (Fernandes, 1995, p. 1.10).

No entanto, tem muito a ver. Há aí um diagnóstico e uma proposta de ação. O diagnóstico é integralmente fiel às interpretações que já estão contidas em Sociedade de classes e subdesenvolvimento, de 1968, e em A revolução burguesa no Brasil, de 1975. A proposta de ação corresponde fielmente à linha do sociólogo e da escola de que ele foi uma das maiores figuras. Em sua concepção a Sociologia é uma ciência que interpreta e uma consciência que interfere. São momentos bem distintos, o do conhecimento e o da ação, o do objeto (e da objetividade) e o do sujeito e da luta. Essa separação sempre esteve claramente presente na sociologia de Florestan Fernandes. Ganhou força, sobretudo, com sua participação na Campanha de Defesa da Escola Pública, entre o final dos anos cinqüenta e o início dos anos sessenta. Com base nessa experiência de intervenção na realidade social, ele mesmo disse:

"O problema diz respeito à natureza do conhecimento científico. Se esse conhecimento é comunicado de uma ou de outra maneira, ou se o investigador está exposto ou não ao contato com vários tipos de público, isso não afeta a natureza do conhecimento científico" (Fernandes, 1978, p. 61.)

Em nome justamente da neutralidade ética na produção do conhecimento científico, ele sempre recusou a tese do cientista falsamente pudico, que se recusa a pôr sua sociologia a serviço da sociedade, mantendo-se reservadamente protegido entre as paredes de gabinetes e laboratórios. Aliás, é dele a idéia de que, na impossibilidade da experimentação nas ciências sociais, a verificação da validade do conhecimento sociológico se dá na prática. É a sociedade que verifica a verdade do sociólogo.

O professor Florestan sempre entendeu que a sociedade oferece à indagação do sociólogo os seus dilemas (e a consciência que tem desses dilemas). A sociedade muda e muda também com a intervenção do sociólogo e da sociologia. Muda, por isso, a consciência que tem de seus problemas e o modo como problematiza as suas dificuldades e seus impasses. Muda, também, portanto, o modo como o sociólogo vê a sociedade e o modo como diagnostica a maneira de transformar a interpretação em ação.

É nesse quadro de referência que está o seu grande legado intelectual e político. Para quem quis entender e teve princípios para fazê-lo, foram essas características de seu legado e do legado de seu grupo original que permitiram atravessar as adversidades da brutal intervenção da ditadura militar na Faculdade de Filosofia, em 1969. Foi a balsa que atravessou a tormenta com a semente fecunda de um modo de pensar e de lutar. Se o Departamento de Sociologia da Faculdade de Filosofia da USP ainda existe e merece respeito da comunidade acadêmica, deve-o sobretudo a ele e a esse grupo notável. 
MARTINS, José de Souza. O professor Florestan Fernandes e nós.Tempo Social; Rev. Sociol. USP, S. Paulo, 7(1-2): 179-186, outubro de 1995.

\section{UNITERMS:}

Florestan Fernandes, Brazilian sociology, São Paulo sociology.
MARTINS, José de Souza. Professor Florestan Fernandes and us. Tempo Social; Rev. Sociol. USP, S. Paulo, 7(1-2): 179-186, october 1995

ABSTRACT: The article deals with the importance of Professor Florestan Fernandes' intellectual and political legacy which can be perceived until nowadays in his successors' works at the Sociology Departament at the University of São Paulo.

\section{REFERÊNCIASBIBLIOGRÁFICAS}

FERnANDES, Florestan. (1953) Ensaio sobre o método de interpretação funcionalista em Sociologia. São Paulo, Universidade de São Paulo, Boletim n ${ }^{\circ} 170$.

. (1960) Ensaios de sociologia geral e aplicada. São Paulo, Livraria Pioneira Editora.

. (1963) A Sociologia numa era de revolução social. São Paulo, Cia. Editora Nacional.

. (1977) A Sociologia no Brasil. Petrópolis, Vozes.

. (1978) A condição de sociólogo. São Paulo, Editora Hucitec.

. (1995) O rateio da pobreza. Folha de S. Paulo, 11 de agosto, p. 1.10.

GiannotTi, J. Arthur. (1960) Notas para uma análise metodológica de $\mathrm{O} C \mathrm{Ca}$ pital. Revista Brasiliense, n 29, maio-junho, p. 60-72.

Lévi-Strauss, C. (1957) Tristes trópicos. Trad. Wilson Martins. São Paulo, Editora Anhembi Limitada.

MERTON, Robert K. (1964) Teoría y estructura sociales. Trad. Florentino M. Torner. México, Fondo de Cultura Económica. 